\title{
ICT approaches to integrating institutional and non-institutional data services for better understanding of hydro-meteorological phenomena
}

\author{
T. Bedrina ${ }^{1}$, A. Parodi $^{1}$, A. Quarati $^{2}$, and A. Clematis ${ }^{2}$ \\ ${ }^{1}$ CIMA Research Foundation, Savona, Italy \\ ${ }^{2}$ Institute of Applied Mathematics and Information Technology - National Research Council, Genoa, Italy \\ Correspondence to: T. Bedrina (tatiana.bedrina@ cimafoundation.org)
}

Received: 18 February 2012 - Revised: 8 May 2012 - Accepted: 17 May 2012 - Published: 18 June 2012

\begin{abstract}
It is widely recognised that an effective exploitation of Information and Communication Technologies (ICT) is an enabling factor to achieve major advancements in Hydro-Meteorological Research (HMR). Recently, a lot of attention has been devoted to the use of ICT in HMR activities, e.g., in order to facilitate data exchange and integration, to improve computational capabilities and consequently model resolution and quality. Nowadays, ICT technologies have demonstrated that it is possible to extend monitoring networks by integrating sensors and other sources of data managed by volunteer's communities. These networks are constituted by peers that span a wide portion of the territory in many countries. The peers are "location aware" in the sense that they provide information strictly related with their geospatial location. The coverage of these networks, in general, is not uniform and the location of peers may follow random distribution. The ICT features used to set up the network are lightweight and user friendly, thus, permitting the peers to join the network without the necessity of specialised ICT knowledge. In this perspective it is of increasing interest for HMR activities to elaborate of Personal Weather Station (PWS) networks, capable to provide almost real-time, location aware, weather data.

Moreover, different big players of the web arena are now providing world-wide backbones, suitable to present on detailed map location aware information, obtained by mashing up data from different sources. This is the case, for example, with Google Earth and Google Maps.

This paper presents the design of a mashup application aimed at aggregating, refining and visualizing near real-time hydro-meteorological datasets. In particular, we focused on
\end{abstract}

the integration of instant precipitation depths, registered either by widespread semi-professional weather stations and official ones. This sort of information has high importance and usefulness in decision support systems and Civil Protection applications. As a significant case study, we analysed the rainfall data observed during the severe flash-flood event of 4 November 2011 over Liguria region, Italy. The joint use of official observation network with PWS networks and meteorological radar allowed for the making of evident finger-like convection structure.

\section{Introduction}

Hydro-Meteorological (HM) science has made significant progress over the last decade. New modelling tools and methodologies for collecting and analysing observational data are now nationally and internationally available (Parodi et al., 2011).

However, the large quantity and complexity of datasets and formats create a significant obstacle in operating with data. As a matter of fact, observational data, HM models and ICT (Information Communication Technology) resources are not generally available at the same time, and are often distributed in an uneven manner between different research institutes, $\mathrm{HM}$ services and operational agencies.

Huge datasets, whether from remote-sensing instruments such as radar networks, or from ground-based observational sensors, need to be easily available. Availability implies easy to locate, easy to obtain the necessary permissions for use and appropriate tools to read the different formats and 
meta-data associated with different data types (Parodi et al., 2011). Moreover, HM scientists are constantly requiring increasing support from the ICT technologies and global certified management tools to deal with extreme HM events such as heavy precipitation and floods.

For these reasons the design, development and deployment of user-friendly interfaces, aiming to abstract HM services provision from the underlying e-Infrastructure complexities and specific implementations, is becoming of paramount importance to Earth scientists.

This study focuses on the special case of personal weather stations (PWS) as a newcomer among the sources of meteorological data in real-time. Due to the growing availability and denser distribution of PWS in many portions of the globe, PWS networks are rapidly becoming providers of additional real-time observational data, potentially able to integrate and enrich the information supplied by official weather networks and, thus, with great importance for populated localities subjected to inundations and landslides.

To support their practical use, we applied the mashup concepts to harvest weather data from different PWS networks over a certain region of interest (Liguria region in northern-western Italy). In our study, the collected data are refined, processed, converted and finally released, by means of visualization tools (i.e., Google Map), to support hydrometeorology scientists and Civil Protection experts in their research and operational activities.

Section 2 introduces the mashup concept. Section 3 describes its application to the case of PWS in Liguria to visualize precipitation data provided by multiple websites/internetplatforms. Section 4 presents the examined case study. Section 5 analyses the usage of PWS and discusses their potential in integrating the data provided by official weather networks (e.g., the Italian Civil Protection Department (ICPD) - rain gauges network). Section 6 gathers conclusions and insights.

\section{Mashup concepts}

In the last decade, the diffusion of Web services technologies, a mix of data format, communication protocols and programming techniques (e.g., SOAP - Simple Object Access Protocol, RPC - Remote Procedure Call, REST - Representational State Transfer, Ajax - Asynchronous JavaScript and Extensible Markup Language, Json - JavaScript Object Notation, etc.), along with new software engineering paradigms like SOA (Service-Oriented Architecture), gave impulse to the development of a huge amount of applications (services) delivered through and accessed via the Web. The use of Web technologies to explore geo-scientific data is now well-established (Amagasa et al., 2007) as well as it is often more frequent to find HM datasets, originated by public or private sources freely exposed, via Web services Application Programming Interfaces (APIs) (Foster et al.,
Table 1. Mashups Pro and Cons.

\begin{tabular}{ll}
\hline Advantages & Disadvantages \\
\hline Reuse of existing services and data & Dependability issues and QoS \\
No extensive IT skills required & Scalabilty issues \\
Rapid development & Most data source are not made as a \\
& service \\
Cost-efficient & No security mechanism \\
\hline
\end{tabular}

2001). These data are usually provided as weather services such as in the case of NOOA (NOAA's National Weather Service, $\quad$ http://www.nws.noaa.gov/observations.php), Weather Underground (http://www.wunderground.com), Weather Bug (http://weather.weatherbug.com), The Weather Channel (http://weather.com), and CoCoRaHS (Community Collaborative Rain, Hail and Snow Network, http://www.cocorahs.org/, Cifelli et al., 2005). What often lacks is the ability to manipulate, aggregate and re-arrange this heterogeneous information in some flexible way according to continuously changing HM scientists' need.

The concept of mashup has recently become very popular in many fields (Chow, 2007). The main objectives of a mashup solution are usually the combination of data and/or programmes published by external online sources into an integrated experience. In other words, a mashup application involves the (fast) integration of data, frequently gathered by using open APIs, from one place on the web, mixing with relevant information from another place on the web and their visualization through a single point of access. For this reason it seems a promising solution to respond to the multiple data-related activities into which HM researchers are daily involved (e.g., finding and retrieving high volume data; learning formats and developing readers; extracting parameters; performing filtering and mask; developing analysis and visualization tools). The system discussed in Williams et al. (2011) wraps Weather Underground data to provide user access through an interoperable interface. The system also provides a mechanism for estimating the uncertainty and bias of the Weather Underground data providing users with more detailed information. In Wang et al. (2009) the authors use some mashup mechanism to allow users to explore existing spatial data and hypothetical future scenarios in a real-time 3-D environment. Data included, i.e., weather conditions and real-time traffic, are visualized in real-time to enhance the reality of emergency training scenarios.

As summarized in Table 1, mashup approach has a number of advantages and disadvantages. From the HM researcher point-of-view and looking at the most desiderate operations (merging heterogeneous data and light map visualization), it is clear that, a well-designed mashup may represent an almost ideal solution. Particularly interesting is the ability to reuse existing data and services, through a quickly developed application, without requiring great IT skills. Moreover the 


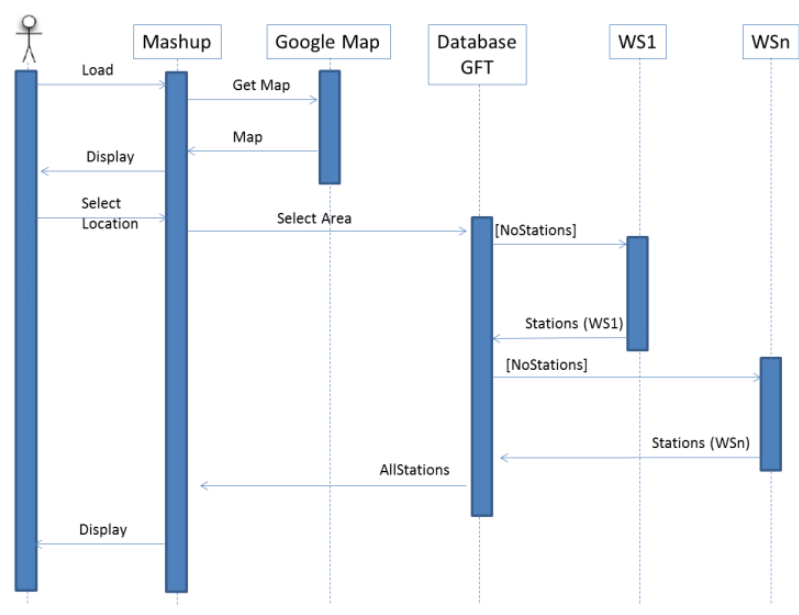

Fig. 1. UML sequence diagram of the retrieving and visualization of weather stations data.

kind of pursued functionalities are only marginally affected by the typical disadvantages of mashups. Probably most critical is the frequent unavailability of a clear interface to access data.

As briefly outlined in the following section, our mashup solution leverages on the data management features provided by Google Fusion Table (GFT) (Gonzalez et al., 2010; Bradley et al., 2011) cloud-based service. GFT, due to its geographical capabilities, perfectly integrates with the Google Map visualization tool, and supplies a basic set of database functionalities that we used to improve query performance and to ease the deployment of our application.

\section{Mashup application: the Liguria region case}

In the present work, mashup techniques are used in order to harvest weather data from PWS available in the Liguria region and neighbouring areas, and successively refine and process these data, thus, providing usable information. The rearranged data are then released, by means of visualization tools (i.e., Google Maps Javascript API V3 Basics), to support HM scientists in their auxiliary role as scene-providers towards Civil Protection needs.

The UML (Unified Modelling Language) sequence diagram (Booch et al., 1999) of Fig. 1 depicts the initial interactions between users and the mashup application. When the user selects the location of the specific region whose precipitation data he/she is interested in, the mashup application proceeds with the retrieving of the results by seeking the data from a set of (fixed/known) weather sites (e.g., WS1, $\ldots$, WSn). As a result a set of geo-referenced points, each accounting for an observation station, is highlighted on the map. Each point is a clickable object (marker) through which a set of more detailed static information about the station is

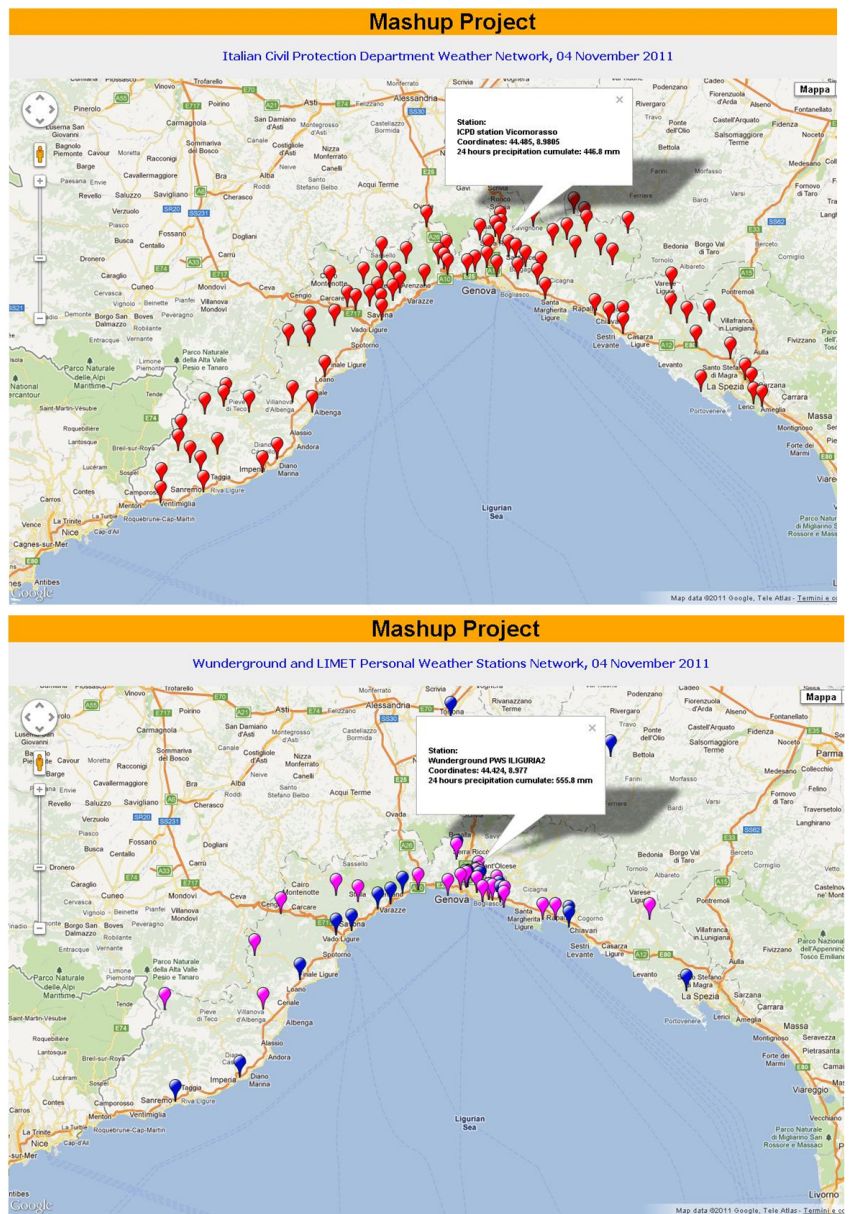

Fig. 2. An example of mapping of official ICPD weather stations (red markers) and PWS from Weather Underground (blue markers) and LIMET (purple markers) networks on the Google map.

returned (latitude and longitude coordinates, location, station ID, etc.). By interacting with a marker the meteorological parameters recently registered at that station are retrieved by querying the weather service site that collects the data from that specific station, and finally shown to the user, Fig. 2.

The majority of weather sites generally supply two types of query: one returning a set of stations (for a given country, city or latitude and longitude coordinates) and another that, given some station identifier (code), retrieves the observations recorded for a certain period (e.g., instant values). Our application follows this querying pattern, thus, allowing a more rapid rendering of the real presence of weather stations for a given region, leaving the user to decide which station(s) to query. This separation, however, did not avert a more comprehensive query mechanism capable to extract weather data from a pool of stations. In the case of the operation that involves a set of points (for example an interpolation function), the previous second steps had to be modified and substituted by some sort of loop that retrieves all the observed 
data from the stations in the set and visualizes the results in one shot.

Given this two-steps interaction scheme, the role of the database component is due to a pair of performance reasons. Firstly, when the stations of a given region have been already retrieved, if stored on the database, no further query is required (Fig. 1). Secondly, the decision to adopt GFT enabled the coupling stations/data markers on a map in an almost immediate way, thus, allowing the rendering of relevant information without any further query (and with quite reduced programming effort).

In our mashup application, we have involved three different data sources (Fig. 2): the official one of the Italian Civil Protection Department and two PWS sources (i.e., Weather Underground and LIMET), which supply their data in open use, free of charge, without any technical constraint or access policy.

\subsection{ICPD weather network description}

The official weather network of ICPD consists of more than 3900 stations equipped by different sensors and distributed quite evenly over Italy, with density of grid about 1 station every $75 \mathrm{~km}^{2}$. The meteorological data (temperature, wind velocity, precipitation, pressure, humidity, snow depth, etc.) are registered and transmitted to ICPD server periodically. Such official observational data are not freely accessible: data utilisation requires an authorised access. The number of the official stations and sensors continues to grow, but despite of this fact, often also such dense network cannot provide sufficient coverage of an area affected by extreme hydrometeorological event, which can be very intense and highly localised in space and time, as it is observed for the Mediterranean storms (Ferraris et al., 2002). Therefore, additional sources of reliable, proven near-real-time weather observational data are often desired especially in highly-impacting hydro-meteorological scenarios: such supplementary source can be represented by non-institutional open-use networks.

\subsection{Semi-professional networks: Weather Underground and LIMET}

The Weather Underground, Inc. (http://www.wunderground. com) is a global non-institutional network, which operates more than 30000 weather stations located around the globe. It manages stations owned by government agencies and international airports and registered in Weather Underground network, and also a widespread network of PWS. The PWS are registered by individual users, meteorological enthusiasts, who manage commercially available semi-professional grade weather stations mounted in gardens, roofs and courtyards. The current weather conditions are collected directly from the weather stations in near-real-time with renewal period about every 3-5 min and provided on-line. Weather Underground network manages about 700 PWS over Italy among
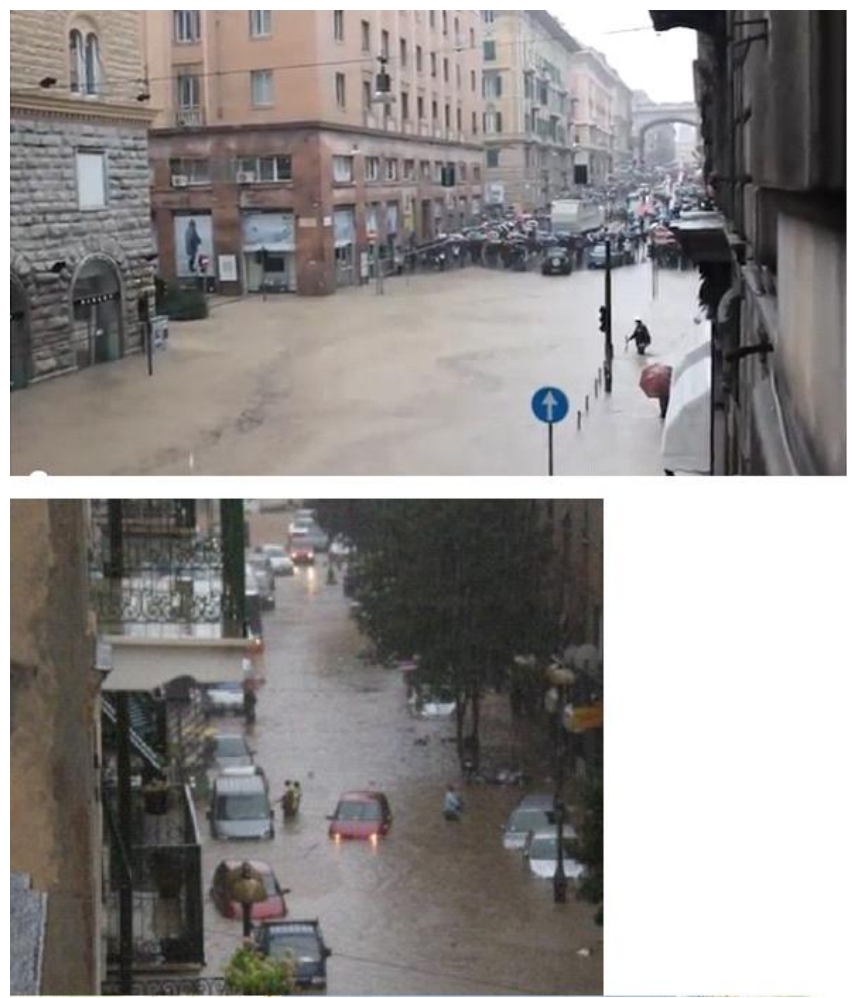

Fig. 3. Flash flood in Genoa on the 4 November 2011 (from the http://www.rete24.com).

them there are about 30 PWS in Liguria region. The Weather Underground official website supplies a set of APIs, which allows access to a number of weather web services aimed to different purposes. The developer can use the data feed to display the current weather conditions, forecasts, hurricanes, weather alerts and other on its proper web application.

The second PWS network, we integrated in our mashup, is operated by the Meteorology Association of Liguria - LIMET (http://www.centrometeoligure.it), a voluntary non-profit alliance of citizen scientists, owners of semiprofessional weather stations assembled into one weather network. Actually the association manages 89 PWS over the Liguria region, Italy, which provides every 3-5 min current weather observational data. One of the remarkable functionality of the LIMET web site is the interactive map of Liguria region with the PWS displayed on it with the current weather parameters updated every 3-5 min (http://www. centrometeoligure.it/rete/reteosservativa.php).

\section{The case study: the flash-flood event in Genoa on 4 November 2011}

To demonstrate the importance of integrating the official observation network with the non-institutional weather networks we carried out an analysis on the flash-flood event that occurred in Genoa city, on the northwest coastline of the 


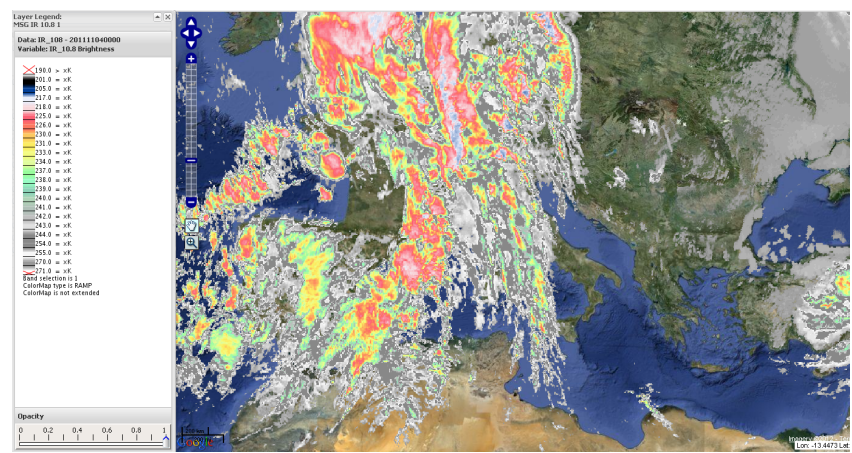

Fig. 4. Infrared temperature image at 00:00 UTC, 4 November 2011. The synoptic scale frontal system affecting western Europe is shown.

Mediterranean sea, on 4 November 2011. In that date about $450 \mathrm{~mm}$ of rain depth - nearly a third of the average annual rainfall (Frei and Schar, 1998) - came down in six hours. Six people were killed, hundreds of shops were flooded, and streets piled with cars (Fig. 3).

The synoptic-scale system responsible for the Genoa event was located over Western Europe on 3-5 November and was characterised by a very deep low-pressure structure (Fig. 4), which established an intense and moist streamflow from the south/southeast impinging against Liguria Apennines ridge, which exceeds up to $1500 \mathrm{~m}$ in very short distance from the sea. The west of Liguria was mainly affected by widespread rains, while the heavy rainfall was concentrated in the centre of the region in Genoa city extending to the west due to a strong convergence of the flow of Scirocco wind (warm, humid airflow moving to the northwest).

The main area of interest affected by the flash-flood event, the basin of the Bisagno torrent and one of its affluents, is the Ferregiano. Bisagno is the torrent in the centre of Ligurian region, passing through the Genoa city, with a basin area of $93 \mathrm{~km}^{2}$, a length of $25 \mathrm{~km}$ and a time of concentration of $2 \mathrm{~h}$. The Bisagno basin is orographically complex and heavily urbanized (because of the presence of the Genoa city), as is most of the small catchments along the Mediterranean coastlines. The Fereggiano creek is one of the remaining withdraw affluents of Bisagno torrent, with a basin area about $3.75 \mathrm{~km}^{2}$ and having its terminal portion (about $800 \mathrm{~m}$ ) passing through the cement pipe under the street coverage up to the outflow to Bisagno torrent. The maximum flow under pressure that could be discharged by the final underground section is in the order of $50 \mathrm{~m}^{3} \mathrm{~s}^{-1}$.

\section{Observational data analysis}

The torrential rainfall event that affected the centre of Genoa city, on 4 November 2011 from 09:00 to 15:00 UTC, was characterised by a tremendous spatial variability and due to
Table 2. The maximum precipitation depth in $1 \mathrm{~h}, 24 \mathrm{~h}$ precipitation cumulate registered by LIMET PWS "Quezzi" and nearest ICPD weather stations.

\begin{tabular}{lrr}
\hline $\begin{array}{l}\text { Weather stations } \\
\text { stations }\end{array}$ & $\begin{array}{r}24 \mathrm{~h} \\
\text { cumulate, } \\
\mathrm{mm}\end{array}$ & $\begin{array}{r}\text { Max 1 h } \\
\text { cumulate, } \\
\mathrm{mm}\end{array}$ \\
\hline ICPD "Vicomorasso" & 444.8 & 168.8 \\
ICPD "Gavette" & 362.4 & 120.6 \\
LIMET PWS "Quezzi" & 555.8 & 166.1 \\
\hline
\end{tabular}

a finger-like isolated and auto-regenerating convective structure (Fig. 5).

One of the PWS of the LIMET network, located in the Fereggiano sub-basin, registered the maximum observed rainfall depth of the event: about $450 \mathrm{~mm}$ of precipitation from 09:00 to 14:00 UTC and about $550 \mathrm{~mm}$ during the 24 hours. The maximum rainfall depth registered in one hour, from 11:00 to 12:00 UTC, by the same station, was more than $160 \mathrm{~mm}$ (Fig. 6, Hyetograph Quezzi, upper panel). Using the data of this station, the peak flow value in the Fereggiano creek was estimated about $180 \mathrm{~m}^{3} \mathrm{~s}^{-1}$, which is more than three times the discharge that the final underground segment is able to manage. Thus, the largest part of the flow engorged by clay sediment and trash passed on the surface along the street. The water depth on the street exceeded, in some places, $1 \mathrm{~m}$ and velocities were up to a few $\mathrm{m} \mathrm{s}^{-1}$.

The comparison between the data provided by the LIMET PWS station and the data of the nearby ICPD stations can allow tackling two important topics:

- to discuss the reliability of the non-official data for this specific case study;

- to gain a deeper understanding of the spatial-temporal structure of the auto-regenerating convective cell.

Thus, the hyetograph of the ICPD station, namely "Gavette", nearest to the LIMET one is shown in Fig. 6 (middle panel): the "Gavette" station is situated about $1.8 \mathrm{~km}$ to northwest of the LIMET PWS. The "Gavette" ICPD station registered about $350 \mathrm{~mm}$ of precipitation from 09:00 to 14:00, and the hourly maximum from 11:00 to $12: 00$ UTC was about $120 \mathrm{~mm}$ as shown in Table 2. The difference between official and PWS measurements is roughly $100 \mathrm{~mm}$ for the 09:00-14:00 UTC time-window and $30 \mathrm{~mm}$ for the hourly maxima. This can motivate concerns on the quality of the LIMET PWS data, however, these data have been professionally validated (LIMET, personal communication, 2012) in agreement with the WMO criteria (Lanza and Vuerich 2009). Then to further understand these differences in gradients between gauges, the use of an integrated quantity can be valuable: Fig. 7 shows the persistence of the 4 November structure indicated by the period of time (hours between 09:00 UTC and 15:00 UTC) where reflectivity was above a 

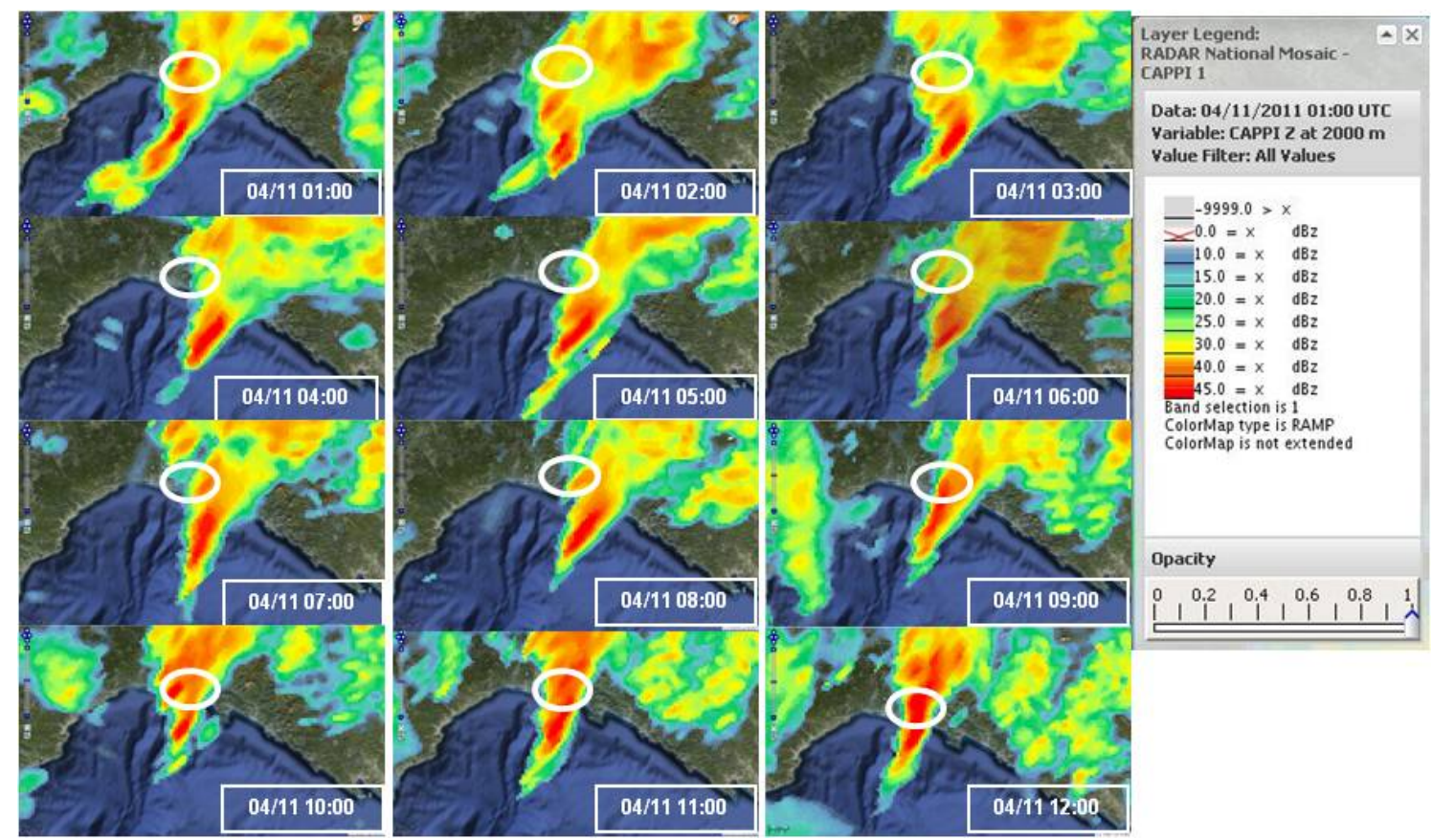

Fig. 5. The hourly developing of the finger-like auto-regenerating structure over the Genoa city, 4 November 2011, reflectivity Cappi at $2000 \mathrm{~m}$ from 01:00 UTC to 12:00 UTC, Italian Radar Mosaic Network, flooded area marked by a white circle.

$40 \mathrm{dBZ}$ threshold. The "Gavette" ICPD station was at the edge of convective cell core, cone-shaped and $10 \mathrm{~km}$ wide, while the LIMET station is closer to the more active cell portion, thus, precipitation amount was largely different in a distance of few kilometres. In addition to that the accuracy of the PWS observations is confirmed to some extent by the ICPD station "Vicomorasso" situated at distance of $6.7 \mathrm{~km}$ north of the LIMET one but located as well as in the most active part of the finger-like convective cell (Fig. 6, lower panel): it as well has registered significant value of precipitation in one hour $(168.8 \mathrm{~mm})$, close to the maximum of the LIMET station ( $166.1 \mathrm{~mm}$, Fig. 6 , upper panel), while the differences between maximums of "Gavette" ICPD station are evident (Fig. 6, middle panel).

To further investigate the validity of our analysis we also made a comparison between the spatial patterns of the total rainfall depth over Liguria region as provided by PWS and by official ICPD stations (Fig. 8). The upper panel of Fig. 8 is the interpolated rainfall map obtained by the observational data of the official ICPD network rain gauge stations, in total 84 during the event $(24 \mathrm{~h})$. The lower panel is the combined total rainfall depth map obtained with observed daily precipitation by the official and PWS networks, for a total of 114 weather stations. The combined map differs from the previous one because it is more detailed in the epicentre of the event, having a larger density of observations. In this case PWS provided additional observational data that with caution and data quality verification have been integrated.

\section{Conclusions}

In the present paper, we introduced the design of a mashup application devoted to the integration of (different) HM datasets and discussed its support to HM activities by examining the case study of a heavy rainfall event recently registered over Liguria region, Italy.

The described approach of collecting weather data spread through the Web, was favoured by the adoption of several APIs supplied by different weather web services, which enabled fast aggregation and visualization of weather information. Particular attention was given to the PWS networks as sources of online real-time weather observational data. The design of a tailored mashup solution enabled the integration of georeferenced static information, current observed weather parameters provided by PWS stations as well as by institutional ones and their subsequent visualization through the Google map tool.

To leverage on the PWS stations weather data, we considered that the stations are properly installed and satisfied with exploitation rules. Primary data quality control tests are conducted to define the orderly functioning of each PWS station during the day. As known, usually PWS networks are characterised by a non-homogeneous and intermittent distribution over an area: for example the density of PWS is high in populated localities and cities. For this reason non-institutional networks could provide basically additional weather data to official observational networks, where each 

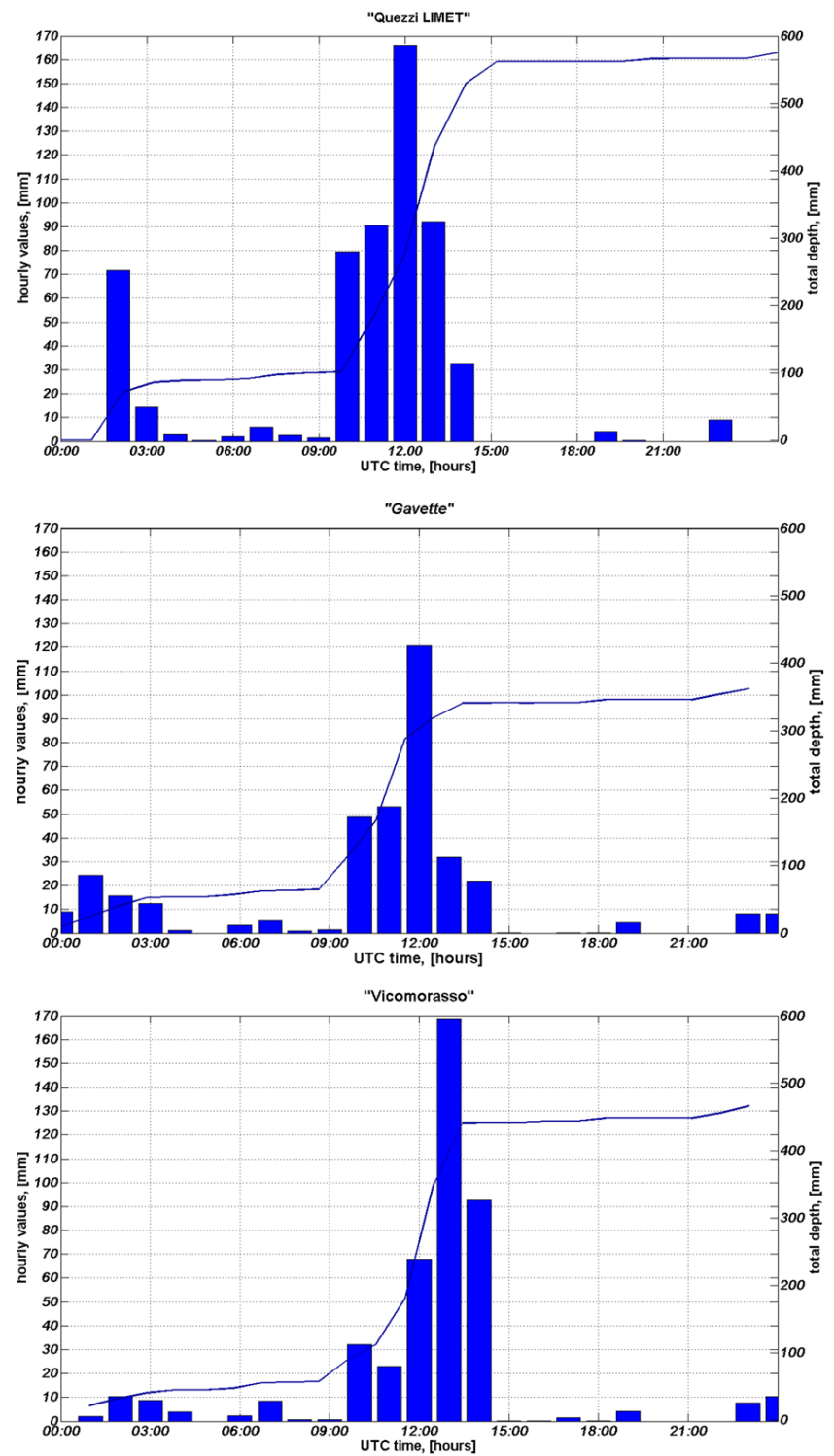

Fig. 6. On the top: rainfall event of the 4 November 2011, hyetograph of the personal weather station of LIMET network "Quezzi". In the middle: hyetograph of the official weather station of ICPD network "Gavette". Below: hyetograph of the official weather station of ICPD network "Vicomorasso".

PWS acts as the point source of georeferenced real-time observational weather information.

To investigate the validity of such a mixed approach, we examined the use of two PWS networks combined with the official data supplied by the ICPD weather network (with density of grid about 1 station every $75 \mathrm{~km}^{2}$ ), in relation to the localised torrential rainfall event of the 4 November 2011 over Liguria region, Italy. Such types of intense rainfall field patterns, unevenly distributed (Fig. 7) over small urbanized catchments are typical for Mediterranean and often difficult to instant observing due to number of reasons

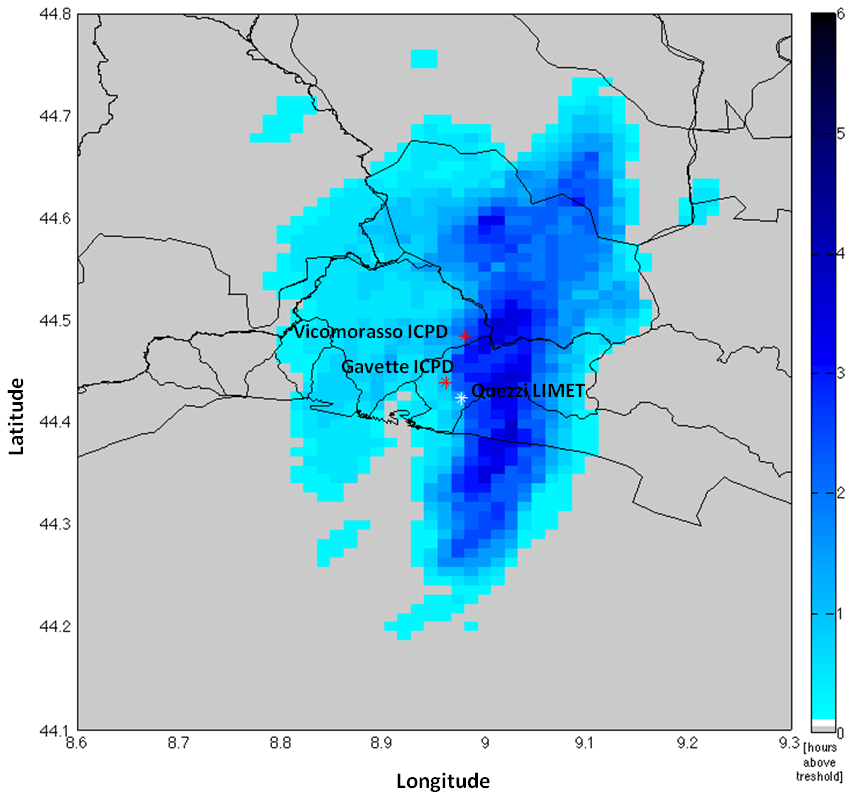

Fig. 7. Persistence of the 4 November structure indicated by the period of time (hours between 09:00 UTC and 15:00 UTC) where reflectivity was above a $40 \mathrm{dBZ}$ threshold. ICPD "Vicomorasso" e "Gavette" stations (red markers), and LIMET PWS “Quezzi” (white marker) are shown
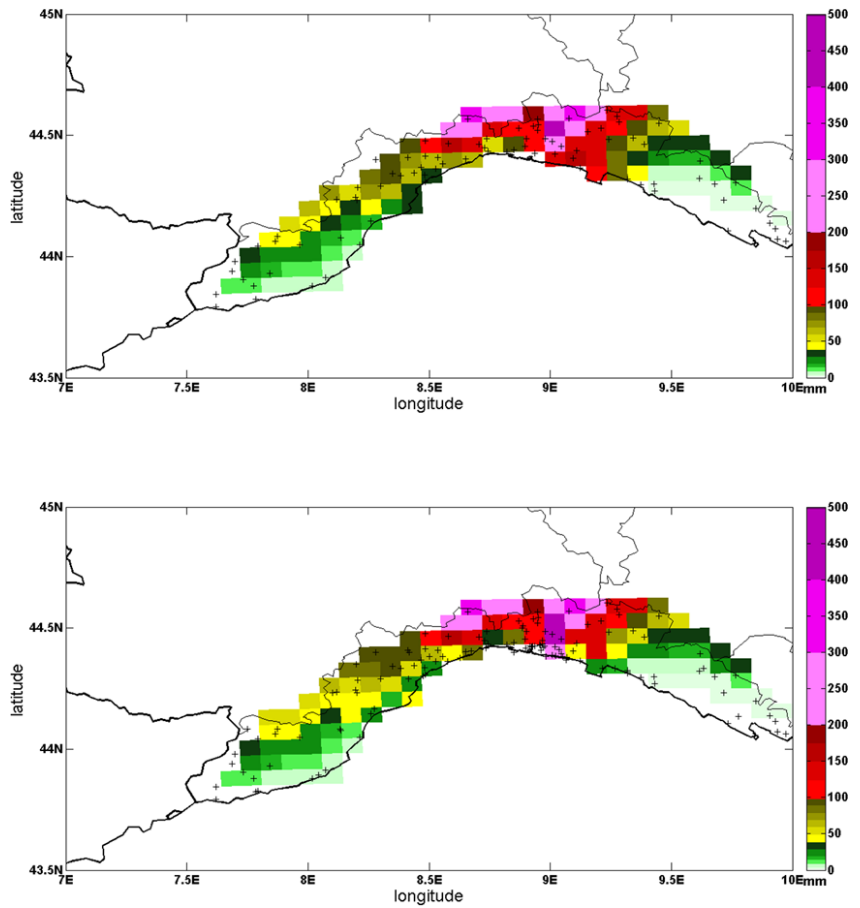

Fig. 8. Daily precipitation maps, (mm), 4 November 2011 over Liguria region, total depth $24 \mathrm{~h}$ registered by: official ICPD network (upper panel), in total 84 rain gauges stations; official ICPD network and PWS (Weather Underground and LIMET) networks (lower panel), in total 132 stations. 
including the insufficient density of weather networks and associated high maintenance expenses as mentioned by Berne et al. (2004). As discussed in Sects. 4 and 5, the availability of free, close-to-reality, real-time weather data, provided by semi-professional weather networks, represented a great opportunity to increase the density of the institutional weather network. Indeed by comparing the maps visualizing the data supplied by both kinds of stations, we acknowledged the validity of a mashup approach, which allowed us to grasp all the available data at once in a more comprehensive way.

The growing amounts of online available PWS real-time data integrated with institutional network observational data may be highly relevant during extreme natural events and disasters over the urban and habitable areas and certainly contribute to a more effective comprehension of the meteorological phenomenon, hence, the deployment of better focused post-event analysis. Further work will be devoted in the future to combine the raingauges data and radar data (Silvestro et al., 2009) with and without the PWS network and see if the resulting fused data show less bias compared to an independent set of raingauges.

Acknowledgements. The authors are grateful to F. Siccardi and $\mathrm{N}$. Rebora for enlightening discussions and useful comments. The comments of the anonymous reviewer and R. Cifelli considerably improved our presentation. Tatiana Bedrina and Antonio Parodi are grateful to the Italian Civil Protection Department and to Regione Liguria for the fundamental support for this research activity. The authors are grateful to LIMET for the data provided. The authors would like to acknowledge the support by the FP7 DRIHM (Distributed Research Infrastructure for Hydro-Meteorology, 2011-2015) project (contract number 283568).

Edited by: N. Rebora

Reviewed by: R. Cifelli and another anonymous referee

\section{References}

Amagasa, T., Kitagawa, H., and Komano, T.: Constructing a Web Service System for Large-scale Meteorological Grid Data, in: 3rd IEEE Int'l Conf. on e-Science and Grid Computing, e-Science, 118-124, 2007.

Berne, A., Delrieu, G., Creutin, J., and Obled, C.: Temporal and spatial resolution of rainfall measurements required for urban hydrology, J. Hydrol., 299, 166-179, 2004.

Boni, G., Parodi, A., and Rudari, R.: Extreme rainfall events: Learning from raingauge time series, J. Hydrol., 327, 304-314, 2006.
Booch, G., Rumbaugh, J., and Jacobson, I.: The Unified Modeling Language User Guide, Addison-Wesley, 1999.

Bradley, E. S., Roberts, D. A., Dennison, P. E., Green, R. O., Eastwood, M., Lundeen, S. R., McCubbin, I. B., and Leifer, I., Google Earth and Google Fusion Tables in support of timecritical collaboration: Mapping the deepwater horizon oil spill with the AVIRIS airborne spectrometer, Earth Science Informatics, 4, 169-179, doi:10.1007/s12145-011-0085-4, 2011.

Chow, S.-W.: PHP Web 2.0 Mashup Projects, in: Packt Publishing, Packt Publishing Ltd., Birmingham, B27 6PA, UK, 304, ISBN13: 978-1-84719-088-8, 2007.

Cifelli, R., Doesken, N., Kennedy, P., Carey, D., Rutledge, S. A., Gimmestad, C., and Depue, T.: The community collaborative rain, hail, and snow network: Informal education for scientists and citizens, B. Am. Meteorol. Soc., 86, 1069-1077, 2005.

Ferraris, L., Rudari, R., and Siccardi, F.: The Uncertainty in the Prediction of Flash Floods in the Northern Mediterranean Environment, J. Hydrometeor., 3, 714-727, 2002.

Foster, I., Kesselman, C., and Tuecke, S.: The anatomy of the grid: Enabling scalable virtual organizations, Int. J. High Perform. Comput. Appl., 15, 200-222, 2001.

Foster, I.: The Grid: A New Infrastructure for 21st Century, Science Physics Today, 55, 42-47, 2002.

Frei, C. and Schar, C.: A precipitation climatology of the Alps from high-resolution rain-gauge observations, Int. J. Climatol., 18, 873-900, 1998.

Gonzalez, H., Halevy, A. Y., Jensen, C. S., Langen, A., Madhavan, J., Shapley, R., Shen, W., and Goldberg-Kidon, J.: Google Fusion Tables: Web-Centered Data Management and Collaboration, in: SIGMOD'10, Indianapolis, Indiana, USA, June 6-11, 2010.

Lanza, L. G. and Vuerich, E.: The WMO Field Intercomparison of Rain Intensity Gauges, Atmos. Res., 94, 534-543, 2009.

Parodi, A., Morando, M., Rebora, N., Trasforini, E., Siccardi, F., Craig, G.C., Tafferner, A., Kranzlmüller, D., Schiffers, M., Clematis, A., D’Agostino, D., Galizia, and Quarati, A.: DRIHMS: The White Paper, available at: http://www.drihms.eu, ISBN 978-88-906068-0-9, 2011.

Silvestro, F., Rebora, N., and Ferraris L.: An algorithm for realtime rainfall rate estimation by using polarimetric radar: RIME, J. Hydrometeorol., 10, 227-240, 2009.

Wang, P., Bishop, I. D., and Stock, C.: Real-time data visualization in Collaborative Virtual Environments for emergency response, in: Proceedings of the Surveying \& Spatial Sciences Institute Biennial International Conference, Adelaide, Surveying \& Spatial Sciences Institute, 435-441, ISBN: 978-0-9581366-8-6, 2009.

Williams, M., Cornford, D., Bastin, L., Jones, R., and Parker, C.: Automatic processing, quality assurance and serving of real-time weather data, Comput. Geosci., 37, 353-362, 2011. 